\title{
ENTRY, PRODUCT LINE EXPANSION, AND PREDATION
}

\author{
Vincenzo Denicolö, Michele Polo** $\mathcal{E}^{*}$ Piercarlo Zanchettin ${ }^{\dagger}$
}

\begin{abstract}
In the Tourist-Caronte case in Italy, the incumbent, Tourist-Caronte, reacted to entry by entrant Diano by starting to supply a "damaged good" in the sense theorized by Deneckere and McAfee in 1996. We argue that in principle this strategy can be predatory, but it can also be an innocent response to entry. Specifically, the strategy of damaging the good leads to fiercer competition in the low segment of the market, which reduces the rents that the incumbent earns in the high segment, but may allow the incumbent to steal some of the entrant's rents. If this business stealing effect in the low segment of the market is sufficiently strong, the incumbent may find it profitable to expand its product line after entry, even if it does not have any predatory intent. We discuss the welfare effects of this strategy, and we contrast it with predation.
\end{abstract}

\section{INTRODUCTION}

Tourist-Caronte is a ferry-boat company that had run the ferry boat service across the Strait of Messina, the narrow section of water between the eastern tip of Sicily and the southern tip of Calabria, in a quasi-monopoly position for many years. As a monopolist, Tourist-Caronte serviced the route connecting Messina (Sicily) with the closest harbor to Sicily on the mainland, namely Villa San Giovanni. In 1998 a new company, Diano, started to operate a ferry service from a more distant harbor, Reggio Calabria, to Messina. The longer distance and the less accessible location of the Reggio Calabria harbor made this route a low-quality substitute for the main route.

* Professor of Economics, University of Bologna, Italy. E-mail: vincenzo.denicolo@unibo.it. An earlier version of this paper was presented at the CRESSE conference in Corfù in July 2006 and is included in the forthcoming Athens University of Economics and Business conference volume, Abuse of Dominance (Yannis Katsoulakos, ed., 2007).

** Professor of Economics, Bocconi University, Milan, Italy and Fellow, Innocenzo Gasparini Institute for Economic Research. E-mail: michele.polo@uni-bocconi.it. The author acted as economic expert for Tourist-Caronte.

$\dagger$ Lecturer in Economics, University of Leicester, Leicester, United Kingdom. E-mail: pz11@le.ac.uk. An earlier version of this paper was presented at the CRESSE conference in Corfu in July 2006 and is included in the forthcoming Athens University of Economics and Business conference volume, Abuse of Dominance (Yannis Katsoulakos, ed., 2007). 
Yet, due to capacity constraints in the Villa San Giovanni harbor, this was the only way for Diano to enter the market. ${ }^{1}$

As a reaction to entry, after a few months Tourist-Caronte started to offer its own ferry services on the longer route, matching the price of the entrant. Some time later, the price of the service that Tourist-Caronte continued to operate on the main route was slightly reduced as well. Diano sued and the case went to trial. The Italian competition authority (AGCM, Autorità Garante per la Concorrenz a e il Mercato) found that Tourist-Caronte had engaged in predatory behavior. The Appeal decision confirmed the findings of the AGCM.

This relatively little known antitrust case raises various interesting issues. First of all, the incumbent's strategy is intriguing and calls for an economic explanation. The fact that the incumbent reacted to entry by expanding its product line is interesting in its own right. Even more surprising, however, is the particular way in which the product line was expanded. Because the route between Reggio Calabria and Messina is longer, it is not only less convenient for passengers, but also more costly to operate than the main route. In other words, the incumbent expanded its product line by starting to supply what Deneckere and McAfee (1996) call a damaged good. A good is damaged when it is of lower quality and yet is more costly to produce than another available good.

Deneckere and McAfee (1996) suggest that damaged goods can be used by monopolistic firms to better discriminate between heterogeneous consumers. They show that, when such discrimination is profitable, typically it is socially desirable and can even represent a Pareto improvement. However, the conditions under which damaging goods can be a profitable discriminating (pro-competitive) strategy for a monopolist are rather demanding. Anderson and Dana (2005) show that in general a monopolist price discriminates if and only if the condition of increasing percentage differences holds. ${ }^{2}$ This condition can be met, but it is rather restrictive when the unit production cost is constant or decreasing in quality, as is the case for damaged goods. For instance, the supply of damaged goods is never profitable in the standard Mussa-Rosen model of vertical differentiation where utility is linear in quality (see Mussa and Rosen, 1978).

As a matter of fact, Tourist-Caronte had not been supplying the damaged good (that is it had not been operating the ferry service on the longer route) while it held a monopoly position; it only started to do that after entry by Diano. This suggests that damaging goods can be a profitable response to entry under more general conditions that it is a profitable price discrimination

${ }^{1}$ Both available piers and queuing lines were limited. A large part of the Villa San Giovanni harbor is reserved for Italian Railways, which provide transport for trains and other vehicles across the Strait and before the entry of Diano were Tourist-Caronte's only competitor.

2 This condition requires that the ratio of the marginal social value from an increase in product quality to the total social value of the good increases with consumers' willingness to pay. 
device for a monopolist. This paper develops a very simple model where the incumbent would not supply damaged goods in the absence of entry. However, if a new firm enters the market and offers a low-quality product, damaging goods can become profitable and can indeed be the best strategy available to the incumbent to respond to entry-even if it anticipates that the entrant will remain in the market. In this sense, post-entry product proliferation need not be a foreclosure strategy: It can be an "innocent" reaction to a more competitive market environment. This distinguishes our theory from the notion of brand proliferation as an entry deterrence device proposed by Schmalensee (1979) and Eaton and Lipsey (1979).

The Tourist-Caronte case also provides an interesting illustration of several antitrust concerns about unilateral practices of a dominant firm. According to a broadly accepted taxonomy, abusive practices can be exclusionary or exploitative. Damaging goods might be considered an exploitative abuse if it is adopted by a discriminating monopolist to better extract consumers' surplus. It might also be considered an exclusionary practice if it is adopted to foreclose actual or potential competitors. From an antitrust perspective, the relevant issue is therefore whether a strategy of post-entry product line expansion implemented by damaging goods may harm consumers either directly (exploitative abuse) or indirectly (through market foreclosure), or may simply be an adaptation to the changed market environment after entry. Deneckere and McAfee's result, that damaging goods tends to have benign welfare effects when it is used by a price discriminating monopolist, dispels most of the concerns that this practice may be an exploitative abuse. This paper contributes to an assessment of the still unsettled issue of whether the practice is exclusionary when it is used as a response to entry. Our result suggests caution in the antitrust evaluation of product line expansions after entry. Incumbents engaging in such a strategy can have predatory intents, but damaging goods can also be an innocent response to entry. Therefore, we argue that antitrust authorities should not take post-entry product line expansion as a proof of a predatory intent, but should run the standard tests to distinguish predatory from innocent behavior. ${ }^{3}$ Our model also offers some suggestions to identify cases where the "innocent" explanation of the incumbent's strategy is more likely to hold true.

The rest of the paper is organized as follows. In Section II we illustrate our argument with a numerical example. Section III generalizes the example using a simple model of vertical differentiation. Section IV discusses the welfare effects of damaging goods in our model, and Section V discusses the implications of the model for competition policy. Section VI offers some concluding remarks.

${ }^{3}$ The AGCM recognized that post-entry product line expansion by the incumbent is not per se predatory and did run a predatory price test. After developing our model, we discuss in greater detail the price test run by AGCM. 


\section{A NUMERICAL EXAMPLE}

In this section we use a numerical example to demonstrate the possibility that damaging goods is an optimal response to entry. We use the example to identify the main effects, and to clarify the logic underlying the profitability of such a strategy. To distinguish our explanation of damaged goods from that of Deneckere and McAfee (1996), we use a numerical example that is consistent with the Mussa-Rosen utility function. This function is linear in quality, in which case supplying damaged goods cannot be a profitable strategy for a price discriminating monopolist.

Consider then a vertically differentiated industry with two firms, an incumbent and a potential entrant. They supply a good that can be produced in two quality levels, high and low. The good is indivisible and each consumer buys either zero or one unit of the good. Consumers' net utility from purchasing one unit of the good is the difference between their willingness to pay and the price. There are two consumers, $A$ and $B$. $A$ is willing to pay 10 for the high-quality good and 5 for the low-quality, while $B$ 's willingness to pay for the high- and low-quality goods is 4 and 2 , respectively. ${ }^{4}$ Normalize to zero the unit cost of the high-quality good, and let $c_{\mathrm{I}}=0$ be the incumbent's unit cost for the low-quality good (the example can be easily perturbed to allow for $c_{\mathrm{I}}>0$ ). Assume that the entrant is unable to produce the high-quality good, and is also less efficient than the incumbent in supplying the lowquality good: $c_{\mathrm{E}}=3 / 2>c_{\mathrm{I}}=0$. Note that the low-quality good can be interpreted as a damaged good in that it is equally or more costly to produce than the high-quality good.

For completeness, we first show that in our example damaging goods cannot be a profitable strategy for a monopolist. The monopolist's best strategy is to offer only the high-quality good at a price of 10 , thereby serving consumer $A$ and earning a profit of 10. If the monopolist tried to sell the high-quality good to both consumers, it would have to lower the price to 4 , with a profit of 8 . If the monopolist tried to price discriminate, it could sell the low-quality good at a price of $p_{\mathrm{L}}=2$, but then could not charge more than $p_{\mathrm{H}}=7$ for the high-quality good, as consumer $A$ can assure herself of a rent of 3 by purchasing the low-quality good. The incumbent's total profits would therefore fall to 9 . Therefore, a monopolist would supply only the high-quality product and serve only consumer $A$, earning a profit of $10 .^{5}$

${ }^{4}$ To see that the example is consistent with the Mussa-Rosen utility function $v q-p$, where $p$ is price, $q$ is quality, and $v$ is a parameter that measures consumers' willingness to pay for quality, one can imagine that $q_{\mathrm{H}}=2, q_{\mathrm{L}}=1, v_{\mathrm{H}}=5$, and $v_{\mathrm{L}}=2$.

${ }^{5}$ Supplying the low-quality good can be profitable if utility is nonlinear in quality. For example, if $B$ 's willingness to pay for the low-quality good was 3 rather than 2 , then a monopolist would prefer to price discriminate by charging $p_{\mathrm{H}}=8$ and $p_{\mathrm{L}}=3$. Pricing this way, the monopolist would sell one unit of the high-quality good to consumer $A$ and one unit of the low-quality good to consumer $B$, earning total profits of 11 . 
Now suppose that the entrant enters. By assumption, this means that the entrant supplies only the low-quality good. We assume that if entry occurs, the incumbent chooses which goods to supply, and then the firms engage in price competition.

Suppose that the incumbent chooses to continue to supply only the highquality good. It is clear that there can be no equilibrium in which the entrant serves high-type consumers. Therefore, there are only two possible candidate equilibria, in which the incumbent respectively accommodates or fights. In the accommodating equilibrium, the incumbent serves only consumer $A$, leaving consumer $B$ for the entrant. In the fighting candidate equilibrium, the incumbent serves both consumers. If the incumbent accommodates, the entrant will price the low-quality good at 2 and serve consumer $B$. In order for the incumbent to sell the high-quality product to consumer $A$, the price must be not larger than 7 . Thus, under accommodation the incumbent's profit is 7 . If the incumbent fights, it lowers the price of the high-quality product to $7 / 2$, such that consumer $B$ is indifferent between buying the high-quality good from the incumbent and buying the lowquality good from the entrant at the lowest price the entrant can charge, which is $p_{\mathrm{L}}=3 / 2$. With a price of $7 / 2$ the incumbent now sells two units, earning again a profit of 7 . In our example, if the incumbent continues to supply only the high-quality good, it is indifferent between accommodating and fighting. This means that, if damaging goods were not an available strategy, both candidate equilibria are equilibria of our game. (Again, one can easily perturb the example so as to break the indifference.)

Alternatively, the incumbent can start supplying the low-quality good. If the incumbent supplies the low-quality good, Bertrand competition drives its price to the entrant's cost: $p_{\mathrm{L}}=3 / 2$. By purchasing the low-quality good at $p_{\mathrm{L}}=3 / 2$, consumer $A$ would earn a rent of $7 / 3$. Therefore, the maximum price that the incumbent can charge for the high-quality good is $13 / 2$. With $p_{\mathrm{H}}=13 / 2$ and $p_{\mathrm{L}}=3 / 2$, the incumbent sells one unit of the high-quality good and one unit of the low-quality good, and so its total profit is 8 . Therefore, damaging goods is the best strategy for the incumbent.

To understand the effects at work in this example, let us first compare the strategy of damaging goods with that of accommodating entry. Note first of all that, even if the entrant supplies only the low-quality good and serves only low-type consumers, entry constrains the price that the incumbent can charge for the high-quality good. This follows from the fact that the availability of the low-quality good creates an outside option for high-type consumers, who could now earn a positive rent by purchasing the low-quality good. When the incumbent accommodates, entry reduces the price it can charge for the high-quality good from $p_{\mathrm{H}}=10$ to $p_{\mathrm{H}}=7$. When the incumbent chooses the damaging strategy, supplying the low-quality good in competition with the entrant further reduces the price of the low-quality good. The hightype consumers' outside option further improves, and this further reduces 
the price that the incumbent can charge to $p_{\mathrm{H}}=13 / 2$. This "indirect competition effect" reduces by half the incumbent's profits realized in the high segment of the market and makes the strategy of damaging goods relatively less attractive.

In a related framework, this indirect competition effect has been identified by Judd (1985). He notes that "once entrants are in an industry, an incumbent will often want to withdraw some goods to prevent competition with the entrant from reducing profits on other goods" (p. 153). However, to the extent that the incumbent is more efficient than the entrant in providing the low-quality good, the incumbent nets a positive profit from supplying the low-quality good. In our numerical example, the price of the low-quality good falls to $p_{\mathrm{L}}=3 / 2$, which means that the incumbent (who supplies the low-quality good at zero cost) nets a rent of $3 / 2$ in the low segment of the market. Therefore, the incumbent steals the business from the entrant. This "business stealing effect" obtained in the low segment of the market makes the strategy of damaging goods relatively more attractive. Damaging goods is therefore more attractive than accommodating in the low segment while it is less profitable in the high segment of the market. In our numerical example, the positive business stealing effect dominates the negative indirect competition effect, making damaging goods preferable to accommodating.

Reversed effects drive the comparison between the strategy of damaging goods and that of fighting. By fighting, the incumbent sells the high-quality good to low-type consumers and so it earns a larger rent, $7 / 2$ rather than $3 / 2$, in the low segment. The difference is entirely due to the fact that the incumbent, in the fighting case, serves low-type consumers more efficiently (with a better product) than when it damages the good. In the example, low-type consumers are indeed served at the same (zero) cost but now they obtain a good that they value more (4 rather than 2). Because the entrant exerts the same competitive pressure in both cases, this efficiency gain fully translates into higher rents for the incumbent in the low segment. We call this effect the "efficiency effect." However, when the incumbent reacts to entry by fighting, that is by selling the high-quality goods to low-type consumers, the price the incumbent can charge to high-type consumers is reduced compared with the damaging strategy (7/2 instead of 13/2) to embark also the low-type consumers, and the indirect competition effect in the high segment of the market now works in favor of damaging goods. Hence, damaging the good rather than fighting the incumbent is gaining in the high segment and losing in the low one. In our numerical example the net effect favors the strategy of damaging the good.

\section{AN ILLUSTRATIVE MODEL}

In this section we generalize the numerical example using a very simple model of entry and product line decision with vertically differentiated products. 
As in the example, we consider a vertically differentiated industry with an incumbent $(I)$ and a potential entrant $(E)$. The good can be produced at two quality levels, high $\left(q_{\mathrm{H}}\right)$ or low $\left(q_{\mathrm{L}}\right)$ : Both firms can supply the lowquality level while only the incumbent can also produce the high-quality good. The good is indivisible and each consumer buys either zero or one unit of the good. Consumers have a Mussa-Rosen utility function that is linear in quality. Specifically, consumer $i$ s net utility from purchasing one unit of the good of quality $q_{\mathrm{k}}$ is

$$
U=q_{\mathrm{k}} v_{\mathrm{i}}-p_{\mathrm{k}}
$$

where $p_{\mathrm{k}}$ is price and $v_{\mathrm{i}}$ is a parameter that measures consumer $i$ 's willingness to pay for quality. There are two types of consumers, $A$ and $B$, with $v_{\mathrm{A}}>v_{\mathrm{B}}>0$ and mass $n_{\mathrm{A}}$ and $n_{\mathrm{B}}$, respectively. We again normalize to zero the unit cost of the high-quality product, and let $c_{\mathrm{I}}=0$ be the incumbent's unit cost for the low-quality good (again, the model can be perturbed to allow for $c_{\mathrm{I}}>0$ ). The entrant is unable to produce the high-quality product, and it is also less efficient than the incumbent in the production of the lowquality good: $0<c_{\mathrm{E}}<v_{\mathrm{B}} q_{\mathrm{L}}$. The condition $c_{\mathrm{E}}<v_{\mathrm{B}} q_{\mathrm{L}}$ ensures that the entrant's costs are lower than the low-type consumer's willingness to pay for the low-quality product, implying that the entrant can obtain positive profits by serving type $B$ consumers. In other words, entry is not blockaded. We first consider the case of monopoly and then proceed to the market equilibrium in the case of entry.

\section{A. Monopoly}

With monopoly and preferences that are linear in quality, damaging goods cannot be a profitable strategy. More precisely, if the gross surplus of type $A$ consumers, $v_{\mathrm{A}} n_{\mathrm{A}}$, is sufficiently high, the monopolist's best strategy is to offer only the high-quality good and price it in such a way as to serve only type $A$ consumers. Otherwise, the best strategy is to supply the high-quality good to all consumers.

To see why, note that in general the monopolist has three options: supply only the high-quality good and serve type $A$ consumers only; supply only the high-quality good and serve both types of consumers; and engage in price discrimination by supplying also the low-quality good and pricing the two goods such that type $A$ consumers purchase the high-quality variant and type $B$ consumers purchase the low-quality variant. Let us consider each possible strategy in turn.

1. If the monopolist supplies only the high-quality good and serves only type $A$ consumers, the price is $p_{\mathrm{H}}=v_{\mathrm{A}} q_{\mathrm{H}}$ and the profits are $\pi_{\mathrm{I}}=v_{\mathrm{A}} q_{\mathrm{H}} n_{\mathrm{A}}$. 
2. If the monopolist supplies only the high-quality good but serves both types of consumers, the optimal price is $p_{\mathrm{H}}=v_{\mathrm{B}} q_{\mathrm{H}}$ and the profits are $\pi_{\mathrm{I}}=v_{\mathrm{B}} q_{\mathrm{H}}\left(n_{\mathrm{A}}+n_{\mathrm{B}}\right)$. Hence, the first strategy is more profitable if $v_{\mathrm{A}} q_{\mathrm{H}} n_{\mathrm{A}}>v_{\mathrm{B}} q_{\mathrm{H}}\left(n_{\mathrm{A}}+n_{\mathrm{B}}\right)$ or

$$
\frac{v_{\mathrm{A}}}{v_{\mathrm{B}}}>\frac{n_{\mathrm{A}}+n_{\mathrm{B}}}{n_{\mathrm{A}}}
$$

Intuitively, if the ratio between the willingness to pay of type $A$ and type $B$ consumers is larger than the percentage increase in sales from selling to $n_{\mathrm{B}}$ more consumers, then serving only the high segment of the market is the more profitable option.

3. Turning to the third option, if the monopolist supplies both quality levels, it will charge $p_{\mathrm{L}}=v_{\mathrm{B}} q_{\mathrm{L}}$ extracting all the rent from low-type consumers. However, because type $A$ consumers have now the option to buy the low-quality good, they will earn a positive rent. Specifically, the optimal price $p_{\mathrm{H}}$ is the highest price that does not induce type $A$ consumers to switch to the low-quality good: $v_{\mathrm{A}} q_{\mathrm{H}}-p_{\mathrm{H}}=v_{\mathrm{A}} q_{\mathrm{L}}-v_{\mathrm{B}} q_{\mathrm{L}}$ or $p_{\mathrm{H}}=v_{\mathrm{A}}\left(q_{\mathrm{H}}-q_{\mathrm{L}}\right)+v_{\mathrm{B}} q_{\mathrm{L}}$. With these prices, the monopolist's profits are $\pi_{\mathrm{I}}=v_{\mathrm{A}}\left(q_{\mathrm{H}}-q_{\mathrm{L}}\right) n_{\mathrm{A}}+v_{\mathrm{B}} q_{\mathrm{L}}\left(n_{\mathrm{A}}+n_{\mathrm{B}}\right)$.

It is easy to check that the first strategy, that is selling the high-quality good only to high-type consumers, dominates the third if equation (1) holds, and the second strategy, that is selling the high-quality good to both types of consumers, dominates the third if inequality (1) is reversed. Hence, damaging goods is never optimal in this setting for a monopolist that does not foresee any entry.

\section{B. Entry}

We now turn to the analysis of the post-entry market equilibrium. By assumption, the entrant can only enter by supplying the low-quality product. (Recall that in the Tourist-Caronte case entrant Diano was unable to operate the ferry service on the shorter route.) We make the standard assumption that firms choose qualities first and then compete in prices. Therefore, once firm $E$ enters, our game has two stages: First, the incumbent chooses its product line, and then firms engage in price competition.

\section{Undamaged Goods}

Suppose that the incumbent chooses to continue to supply only the highquality good. Clearly, in equilibrium the entrant cannot serve high-type consumers (otherwise, the incumbent would have an incentive to undercut the entrant's price). Therefore, there are only two possible candidate equilibria, in which the incumbent respectively accommodates or fights. 
- In the accommodate case (denoted by $a$ ), the incumbent serves only type $A$ consumers, leaving type $B$ consumers to the entrant. In this case the entrant sets $p_{\mathrm{L}, \mathrm{a}}=v_{\mathrm{B}} q_{\mathrm{L}}$ and the incumbent sets the highest price that makes type $A$ consumers choose the high-quality good, that is $p_{\mathrm{H}, \mathrm{a}}=v_{\mathrm{A}}\left(q_{\mathrm{H}}-q_{\mathrm{L}}\right)+v_{\mathrm{B}} q_{\mathrm{L}}$; hence, the incumbent's profits are

$$
\pi_{\mathrm{I}, \mathrm{a}}=\left[v_{\mathrm{A}}\left(q_{\mathrm{H}}-q_{\mathrm{L}}\right)+v_{\mathrm{B}} q_{\mathrm{L}}\right] n_{\mathrm{A}}
$$

- In the fight case (denoted by $f$ ) the incumbent competes for type $B$ consumers with the entrant. In the low segment of the market, a standard Bertrand equilibrium with limit pricing emerges, with the incumbent serving all type $B$ consumers. The entrant sets $p_{\mathrm{L}, \mathrm{f}}=c_{\mathrm{E}}$, and the incumbent sets the highest price that makes type $B$ consumers purchase the high-quality good, that is $p_{\mathrm{H}, \mathrm{f}}=v_{\mathrm{B}}\left(q_{\mathrm{H}}-q_{\mathrm{L}}\right)+c_{\mathrm{E}}$. Consequently, the incumbent earns

$$
\pi_{\mathrm{I}, \mathrm{f}}=\left[v_{\mathrm{B}}\left(q_{\mathrm{H}}-q_{\mathrm{L}}\right)+c_{\mathrm{E}}\right]\left(n_{\mathrm{A}}+n_{\mathrm{B}}\right)
$$

Comparing equations (2) and (3), we conclude that pricing so as to accommodate entry is the best strategy when

$$
\frac{v_{\mathrm{A}}\left(q_{\mathrm{H}}-q_{\mathrm{L}}\right)+v_{\mathrm{B}} q_{\mathrm{L}}}{v_{\mathrm{A}}\left(q_{\mathrm{H}}-q_{\mathrm{L}}\right)+c_{\mathrm{E}}}>\frac{n_{\mathrm{A}}+n_{\mathrm{B}}}{n_{\mathrm{A}}}
$$

The logic behind this condition is similar to that behind condition (1) above. The left-hand side measures the percentage increase in price that the incumbent can enjoy by serving high-type consumers only (in the accommodate case), while the right-hand side measures the percentage increase in volume achieved by serving also low-type consumers (in the fight case).

\section{Damaged Goods}

If, instead, the incumbent supplies also the low-quality good, we are in the damaged good case (denoted by $d$ ). Bertrand competition in the low-quality segment of the market now simply leads to $p_{\mathrm{L}, \mathrm{d}}=c_{\mathrm{E}}$. The price for type $A$ consumers is set, as before, at the highest level that induces those consumers to purchase the high-quality product, that is $p_{\mathrm{H}, \mathrm{d}}=v_{\mathrm{B}}\left(q_{\mathrm{H}}-q_{\mathrm{L}}\right)+c_{\mathrm{E}}$. Notice that the incumbent is more efficient than the entrant in producing the damaged good, and therefore in a limit pricing equilibrium the entrant would serve all the $n_{\mathrm{B}}$ low-type consumers (that is by slightly undercutting the entrant). However, let us assume that the incumbent serves only a fraction $\alpha$, with $1 / 2 \leq \alpha \leq 1$, of type $B$ consumers. This is just a short-cut to capture in a reduced-form model certain effects that may be relevant in the Tourist-Caronte case, such as some degree of horizontal product differentiation 
(different timetables of the service), the existence of capacity constraints, or the threat of antitrust intervention. These effects may weaken the intensity of competition in the low segment of the market allowing the entrant to capture a positive market share. This assumption is, admittedly, ad hoc. However, note that allowing for $\alpha<1$ can only make the strategy of damaging goods less attractive to the incumbent. We recognize that weaker competition would typically result in higher prices, but because here we are concerned only with the profitability of this strategy to the incumbent, introducing the parameter $\alpha$ suffices for our purposes. Thus, the incumbent's profits are

$$
\pi_{\mathrm{I}, \mathrm{d}}=\left[v_{\mathrm{A}}\left(q_{\mathrm{H}}-q_{\mathrm{L}}\right)+c_{\mathrm{E}}\right] n_{\mathrm{A}}+\alpha c_{\mathrm{E}} n_{\mathrm{B}}
$$

\section{Comparison}

We are now ready for a comparison of these strategies. It is interesting to compare the different outcomes distinguishing between the incumbent's profits extracted from type $A$ and type $B$ consumers. We can immediately notice the following simple result:

$$
p_{\mathrm{H}, \mathrm{a}}>p_{\mathrm{H}, \mathrm{d}}>p_{\mathrm{H}, \mathrm{f}}
$$

In general, competition from the entrant lowers the price of the high-quality good through an "indirect competition effect." The extent to which it does so, however, depends on the incumbent's reaction to entry. If the incumbent accommodates, the indirect competition effect is lowest, because the incumbent does not compete in the low segment of the market. If the incumbent damages the good and competes in the low segment of the market with the low-quality good, the indirect competition effect is stronger. However, this effect is strongest if the incumbent fights, that is competes in the low segment of the market with the high-quality good. In this case the incumbent must cut the price of the high-quality good even more because now it wants to sell the high-quality good to low type consumers.

Turning to the low segment of the market, the incumbent does not supply type $B$ consumers in the accommodate case, leaving them to the entrant that as a consequence earns a positive rent. However, the incumbent serves low-type consumers when it fights or damages a good, with a positive "business stealing effect." The profit that the incumbent can extract from the low segment of the market, for any given competitive pressure exerted by the entrant, is however larger when the incumbent serves the low segment efficiently, that is with highquality goods. This is the "efficiency effect" that works in favor of the fighting strategy as against the strategy of damaging goods.

Summing up, if we distinguish the incumbent's profits obtained in the two market segments, for type $A$ consumers the ranking is driven by the "indirect competition effect": Accommodate dominates damage good that, in turn, is more 
profitable than fight. On the other hand, the comparison of the profits from type $B$ consumers lead to the opposite ranking: Fight is more highly profitable than damage good (because of the "efficiency effect"), that in turn is better that accommodate where the low segment is completely left to the entrant (because of the "business stealing effect").

The overall effect, therefore, depends both on the relative size of the two markets, $A$ and $B$, and on the strength of the competitive pressure exerted by the entrant, that in turn depends on its efficiency. Hence, we focus our analysis on the effect of two variables, the size of the high segment of the market, $n_{\mathrm{A}}$, and the cost of the entrant, $c_{\mathrm{E}}$.

Some algebra helps to identify the parameter regions where the subgame perfect equilibrium of our game involves accommodating, fighting, or damaging the good. For each pair of outcomes $g, h=a, f, d$, we can define in the $\left(n_{\mathrm{A}}, c_{\mathrm{E}}\right)$ space a iso-profit locus $n_{\mathrm{A}}^{\mathrm{g}, \mathrm{h}}$ along which the outcomes $g$ and $h$ lead to the same profits for the incumbent, $\pi_{\mathrm{I}, \mathrm{g}}=\pi_{\mathrm{I}, \mathrm{h}}$. Using equations (2), (3) and (5) we get:

$$
\begin{gathered}
n_{\mathrm{A}}^{\mathrm{a}, \mathrm{f}}\left(c_{\mathrm{E}}\right)=\frac{\left(v_{\mathrm{B}} \Delta q+c_{\mathrm{E}}\right) n_{\mathrm{B}}}{\Delta v \Delta q+v_{\mathrm{B}} q_{\mathrm{L}}-c_{\mathrm{E}}} \\
n_{\mathrm{A}}^{\mathrm{a}, \mathrm{d}}\left(c_{\mathrm{E}}\right)=\frac{\alpha c_{\mathrm{E}} n_{\mathrm{B}}}{v_{\mathrm{B}} q_{\mathrm{L}}-c_{\mathrm{E}}}
\end{gathered}
$$

and

$$
n_{\mathrm{A}}^{\mathrm{d}, \mathrm{f}}\left(c_{\mathrm{E}}\right)=\frac{\left[v_{\mathrm{B}} \Delta q+(1-\alpha) c_{\mathrm{E}}\right] n_{\mathrm{B}}}{\Delta v \Delta q}
$$

where the loci are defined over the range for $0 \leq c_{\mathrm{E}}<v_{\mathrm{B}} q_{\mathrm{L}}$, and we have defined $\Delta v=v_{\mathrm{A}}-v_{\mathrm{B}}$ and $\Delta q=q_{\mathrm{H}}-q_{\mathrm{L}}$. Accommodating is better than fighting above the $n_{\mathrm{A}}^{\mathrm{a}, \mathrm{f}}$ locus; accommodating is better than damaging the good above the $n_{\mathrm{A}}^{\mathrm{a}, \mathrm{d}}$ locus; and fighting is better than damaging the good below the $n_{\mathrm{A}}^{\mathrm{d}, \mathrm{f}}$ locus. Therefore, damaging the good is an equilibrium outcome below the $n_{\mathrm{A}}^{\mathrm{a}, \mathrm{d}}$ locus and above the $n_{\mathrm{A}}^{\mathrm{d}, \mathrm{f}}$ locus.

To proceed, notice first of all that the three loci are continuous. Moreover, $n_{\mathrm{A}}^{\mathrm{a}, \mathrm{d}}(0)=0$ and $\lim _{c_{E} \rightarrow v_{B} q_{L}} n_{A}^{a, d}\left(c_{\mathrm{E}}\right)=\infty$ while $n_{\mathrm{A}}^{\mathrm{d}, \mathrm{f}}(0)>0$ and $n_{\mathrm{A}}^{\mathrm{d}, \mathrm{f}}\left(v_{\mathrm{B}} q_{\mathrm{L}}\right)$ is finite. Hence, the two loci intersect at a point $\bar{c}_{\mathrm{E}}$, implying that in the interval $\bar{c}_{\mathrm{E}}<c_{\mathrm{E}}<v_{\mathrm{B}} q_{\mathrm{L}}$ there exists a region, delimited above by $n_{\mathrm{A}}^{\text {a,d }}\left(c_{\mathrm{E}}\right)$ and below by $n_{\mathrm{A}}^{\mathrm{d}, \mathrm{f}}\left(c_{\mathrm{E}}\right)$, in which damaging the good is the equilibrium outcome. (By construction, when two of the loci intersect, all three must intersect at the same point.) Finally, when $\alpha$ increases, that is competition in the low-quality segment becomes harsher, $n_{\mathrm{A}}^{\mathrm{a}, \mathrm{d}}\left(c_{\mathrm{E}}\right)$ becomes steeper and $n_{\mathrm{A}}^{\mathrm{d}, \mathrm{f}}\left(c_{\mathrm{E}}\right)$ becomes flatter, enlarging the region where damaging goods is the equilibrium outcome. 
Table 1. Prices and profits in candidate equilibria

\begin{tabular}{llll}
\hline & Accommodate & Fight & Damage \\
\hline$p_{\mathrm{L}}^{\mathrm{E}}$ & 2 & $c_{\mathrm{E}}$ & $c_{\mathrm{E}}$ \\
$p_{\mathrm{L}}^{\mathrm{I}}$ & 7 & $2+c_{\mathrm{E}}$ & $c_{\mathrm{E}}$ \\
$p_{\mathrm{H}}$ & $7 n_{\mathrm{A}}$ & $\left(2+c_{\mathrm{E}}\right)\left(1+n_{\mathrm{A}}\right)$ & $5+c_{\mathrm{E}}$ \\
$\pi_{\mathrm{I}}$ & & $\left(5+c_{\mathrm{E}}\right)\left(1+n_{\mathrm{A}}\right)$ \\
\hline
\end{tabular}

To illustrate, we now specialize most of the parameters. To be consistent with our numerical example, we assume the following parameters values: $q_{\mathrm{H}}=2, q_{\mathrm{L}}=1, v_{\mathrm{A}}=5$, and $v_{\mathrm{B}}=2$. We also normalize by setting $n_{\mathrm{B}}=1$, while we let $n_{\mathrm{A}}$ and $c_{\mathrm{E}}$ vary in the intervals $n_{\mathrm{A}} \geq 0$ and $0 \leq c_{\mathrm{E}} \leq 2$. Table 1 illustrates the prices and profits in the three candidate equilibria.

The three loci become:

$$
\begin{aligned}
& n_{\mathrm{A}}^{\mathrm{a}, \mathrm{f}}\left(c_{\mathrm{E}}\right)=\frac{2+c_{\mathrm{E}}}{5-c_{\mathrm{E}}} \\
& n_{\mathrm{A}}^{\mathrm{a}, \mathrm{d}}\left(c_{\mathrm{E}}\right)=\frac{\alpha c_{\mathrm{E}}}{2-c_{\mathrm{E}}}
\end{aligned}
$$

and

$$
n_{\mathrm{A}}^{\mathrm{d}, \mathrm{f}}\left(c_{\mathrm{E}}\right)=\frac{2+(1-\alpha) c_{\mathrm{E}}}{3}
$$

respectively.

The loci are depicted in Figure 1. Figure 1 also shows the three regions where accommodate, fight, and damage good are respectively the best strategy for the incumbent. Damage good is the equilibrium outcome when the high segment of the market is not very important $\left(n_{\mathrm{A}}\right.$ small $)$ and the entrant is inefficient $\left(c_{\mathrm{E}}\right.$ large), that is in the northeast region, because the negative indirect competition effect is not too strong while the positive business stealing effect is still significant. ${ }^{6}$

When, instead, the entrant is very efficient $\left(c_{\mathrm{E}}<\bar{c}_{\mathrm{E}}\right)$ it exerts a strong competitive pressure on the price for the high-quality good. When the high segment of the market is large ( $n_{\mathrm{A}}$ large), accommodate, which entails a higher price for the high-quality good, is preferable, while when there are few type $A$ consumers, fight becomes more profitable, because it allows the (relatively more important) low segment of the market to also be served.

${ }^{6}$ When the entrant is very inefficient ( $c_{\mathrm{E}}$ is very large), damaging the good is the equilibrium strategy even when the high segment of the market, $n_{\mathrm{A}}$, is pretty large. 


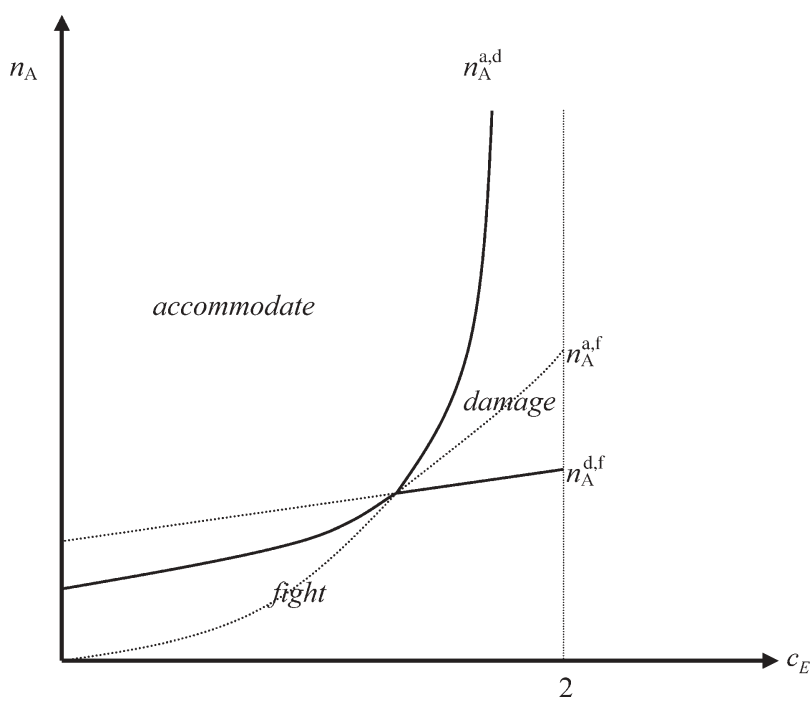

Figure 1.

\section{WELFARE}

What are the welfare effects of allowing the incumbent to damage its goods? That depends on whether fighting or accommodating would be the incumbent's best response to entry if it was now allowed to damage goods. If the incumbent would fight (that is below the $n_{\mathrm{A}}^{\mathrm{a}, \mathrm{f}}\left(c_{\mathrm{E}}\right)$ locus), the market would achieve the first-best optimum where all consumers received the highquality good, with total net social welfare (that is the sum of consumers' surplus and firms' profits) of $\left(n_{\mathrm{A}} v_{\mathrm{A}}+n_{\mathrm{B}} v_{\mathrm{B}}\right) q_{\mathrm{H}}$ (14 in the numerical example of Section II). However, if the incumbent would accommodate (that is above the $n_{\mathrm{A}}^{\mathrm{a}, \mathrm{f}}\left(c_{\mathrm{E}}\right)$ locus), social welfare would amount to $v_{\mathrm{A}} q_{\mathrm{H}} n_{\mathrm{A}}+\left(v_{\mathrm{B}} q_{\mathrm{L}}-c_{\mathrm{E}}\right) n_{\mathrm{B}}$ only (10.5 in the numerical example), because type $B$ consumers would now get the low-quality good and purchase it from the inefficient entrant. By way of contrast, if the incumbent damages the good, social welfare would be $v_{\mathrm{A}} q_{\mathrm{H}} n_{\mathrm{A}}+v_{\mathrm{B}} q_{\mathrm{L}} n_{\mathrm{B}}$ (12 in the numerical example), because now type $B$ consumers get the low-quality good from the (more efficient) incumbent. It is clear that $W^{\mathrm{f}}>W^{\mathrm{d}}>W^{\mathrm{a}}$ for any possible combination of parameters values.

In practice, assessing the welfare effects of a strategy of damaging the good involves answering the following counterfactual: How would the incumbent have responded if it had not been allowed to damage the good? The answer is likely to be very controversial. Our theoretical analysis can, however, provide some hints. Turning back to Figure 1, the region where damaging the good is an equilibrium outcome can be split into two sub-regions, above and below the $n_{\mathrm{A}}^{\mathrm{a}, \mathrm{f}}\left(c_{\mathrm{E}}\right)$ locus. Above the $n_{\mathrm{A}}^{\mathrm{a}, \mathrm{f}}\left(c_{\mathrm{E}}\right)$ locus, prohibiting the 
incumbent from matching the low-quality product would induce the incumbent to accommodate, with a fall in welfare, whereas below the $n_{\mathrm{A}}^{\mathrm{a}, \mathrm{f}}\left(c_{\mathrm{E}}\right)$ locus the incumbent would opt for fighting, improving welfare. Hence, when the top segment is relatively large, we would expect that preventing the incumbent from expanding its product line would reduce welfare.

\section{LESSONS FOR COMPETITION POLICY}

In the last section we showed that the welfare effects of damaging the good are ambiguous, as they depend on what the incumbent would have done if it could not expand its product line. However, even if the welfare effects are negative, few antitrust authorities would condemn a practice that has no exclusionary intent and is an innocent response to entry. The antitrust concerns surrounding the practice of product line expansion are mostly associated with the notion that this practice can have exclusionary effects.

There are two ways in which damaging goods can have exclusionary effects. First, damaging goods can be used to deter entry, as in the models of Schmalensee (1978) and Eaton and Lipsey (1979). Second, it can be a predatory tactic. Here we have nothing to add to the debate on the credibility of spatial preemption, but a few remarks on predation are in order.

In the Tourist-Caronte case, the AGCM was concerned that Caronte's strategy may be predatory. In particular, the AGCM held that Caronte was engaging in selective predation, pricing below cost only in the low segment of the market to limit its losses. Of course, any price cut in the low segment of the market inevitably constrains the price that the incumbent can charge in the high segment. Therefore, predating in the low segment of the market reduces the profitability of the high segment as well. However, this indirect competition effect is weaker with damaged goods than without damaged goods.

To illustrate the AGCM theory, suppose that the incumbent wants to constrain the price that can be charged by the entrant to a pre-specified level $\bar{p}_{\mathrm{L}}$. If the incumbent wants to achieve this result by supplying the high-quality good only, the incumbent must charge a price of $v_{\mathrm{B}} \Delta q+\bar{p}_{\mathrm{L}}$, earning $\pi_{\mathrm{I}, \mathrm{f}}=\left(v_{\mathrm{B}} \Delta q+\bar{p}_{\mathrm{L}}\right)\left(n_{\mathrm{A}}+n_{\mathrm{B}}\right)$. If instead the incumbent damages the good and supplies also the low-quality good, it will have to price the low-quality good at $\bar{p}_{\mathrm{L}}$ and the high-quality good at $v_{\mathrm{A}} \Delta q+\bar{p}_{\mathrm{L}}$, with a total profit of $\pi_{\mathrm{I}, \mathrm{d}}=\left(v_{\mathrm{A}} \Delta q+\bar{p}_{\mathrm{L}}\right) n_{\mathrm{A}}+\left(\bar{p}_{\mathrm{L}}-c_{\mathrm{I}}\right) n_{\mathrm{B}}$. If $n_{\mathrm{B}}$ is sufficiently low relative to $n_{\mathrm{A}}, \pi_{\mathrm{I}, \mathrm{d}}$ can exceed $\pi_{\mathrm{I}, \mathrm{f}}$ even if the incumbent makes a loss in the low segment of the market, that is even if $\bar{p}_{\mathrm{L}}<c_{\mathrm{I}}$. This implies that damaging the good can indeed be an efficient, selective predatory strategy.

In practice it may be quite difficult to distinguish between a predatory explanation and an innocent-response-to-entry explanation of the strategy of 
damaging the good, and therefore standard price tests should be used to assess whether the incumbent behavior was predatory. ${ }^{7}$

However, our model suggests that there is no presumption that an incumbent that damages the good to respond to entry has a predatory intent, and it provides some insights as to when an innocent explanation may apply. In particular, damaging the good can be an innocent response to entry when the entrant is not very efficient, and when the high segment of the market is large. The model also suggests that an aggressive response to entry (either fight or damage goods) can be preferable to an accommodating strategy in terms of social welfare.

\section{CONCLUSION}

In this paper we have analyzed the product line and pricing choices of an incumbent that faces a new entrant. The incumbent can offer a high-quality good and a low-quality good, whereas the entrant can produce only the lowquality good. The low-quality good is produced at a unit cost that is at least as large as that of the high-quality good; as such, it can be viewed as a damaged good in the sense of Deneckere and McAfee (1996). Under standard assumptions, an unchallenged incumbent offers only the high-quality good. However, we have shown that the incumbent may react to entry by starting to offer also the low-quality good. Such a move leads to fiercer competition in the low segment of the market, which reduces the rents that the incumbent earns in the high segment, but may allow the incumbent to steal some of the entrant's sales and rents in the low segment. If this business stealing effect in the low segment of the market is sufficiently strong, the incumbent may find it profitable to damage goods as a response to entry. We have discussed the welfare effects of this strategy and contrasted it with the selective predation theory of damaged goods.

7 The AGCM did perform a predatory pricing test, and found that Tourist-Caronte was pricing below its average costs. Tourist-Caronte argued that this is not the appropriate benchmark because most of its costs to run the longer route were not incremental. In particular, it argued that the service on the longer route was operated with ships and crews that were idle. In fact, Tourist-Caronte had entered a large-scale program of modernization of its fleet before Diano's entry, and as a consequence some of its oldest ships were idle. Moreover, after long bargaining with the Unions, Tourist-Caronte agreed not to lay off any employees, even if the new ships required a smaller crew. Hence, a sizeable share of the capital (ships) and labor (crews) cost of operating the service on the longer route would have been borne by Tourist-Caronte anyway, and therefore were not incremental. If the AGCM had run a proper incremental cost test rather than an average cost test, it probably would not have found that Tourist-Caronte's prices were predatory. 
624 Fournal of Competition Law and Economics

\section{REFERENCES}

Anderson, E., Dana, J. 2005. When is Price Discrimination Profitable?, mimeo, Kellog School of Management.

Deneckere, R.J., McAfee, R.P. 1996, Damaged Goods, fournal of Economics and Management Strategy, 5: 149-74.

Eaton, B., Lipsey, R. 1979. The Theory of Market Pre-emption: the Persistence of Excess Capacity and Monopoly in Growing Spatial Markets, Economica, 46: 149-58.

Judd, K. 1985, Credible Spatial Preemption, RAND fournal of Economics, 16: 153-66.

Mussa, M., Rosen, S. 1978. Monopoly and Product Quality, fournal of Economic Theory, 18: 301-17.

Schmalensee, R. 1978. Entry Deterrence in the Ready-to-eat Breakfast Cereal Industry, Bell Fournal of Economics, 9: 305-27. 